\title{
Identification of candidate intergenic risk loci in autism spectrum disorder
}

Susan Walker ${ }^{1}$ and Stephen W Scherer ${ }^{1,2^{*}}$

\begin{abstract}
Background: Copy number variations (CNVs) and DNA sequence alterations affecting specific neuronal genes are established risk factors for Autism Spectrum Disorder (ASD). In what is largely considered a genetic condition, so far, these mutations account for $\sim 20 \%$ of individuals having an ASD diagnosis. However, non-coding genomic sequence also contains functional elements introducing additional disease risk loci for investigation.
\end{abstract}

Results: We have performed genome-wide analyses and identified rare inherited CNVs affecting non-genic intervals in 41 of 1491 (3\%) of ASD cases examined. Examples of such intergenic CNV regions include 16q21 and 2p16.3 near known ASD risk genes CDH8 and NRXN1 respectively, as well as novel loci contiguous with ZHX2, MOCS1, LRRC4C, SEMA3C, and other genes.

Conclusions: Rare variants in intergenic regions may implicate new risk loci and genes in ASD and also present useful data for comparison with coming whole genome sequence datasets.

Keywords: Autism spectrum disorder, Copy number variation, Non-coding DNA

\section{Background}

Newer genomic technologies like high-resolution microarrays and next generation exome sequencing have enabled the identification of many clinically relevant genetic variants for both Mendelian and complex disorders. Yet for many conditions the identified genes account for only a proportion of heritability. This observation coupled with the recognition of the functional relevance of non-genic regions [1] target these genomic segments as candidates for investigation for a role in disease.

ASD encompasses a range of neurodevelopmental disorders characterised by social impairment, communication difficulties and restricted, repetitive behavioural patterns. ASD, which is clinically and genetically heterogeneous, demonstrates high heritability, familial clustering and $\sim 4: 1$ male to female bias. While there has been progress identifying risk genes, most are still unknown [2]. Analyses of rare $(<1 \%$ population frequency) CNVs, insertions and deletions (indels) and point mutations have most convincingly identified synaptic genes such as members

\footnotetext{
* Correspondence: Stephen.Scherer@sickkids.ca

'Program in Genetics and Genome Biology, The Centre for Applied Genomics, The Hospital for Sick Children, Toronto, Ontario M5G 1L7, Canada

${ }^{2}$ McLaughlin Centre, University of Toronto, Toronto, Ontario M5S 1A1, Canada
}

(c) 2013 Walker and Scherer; licensee BioMed Central Ltd. This is an Open Access article distributed under the terms of the Creative Commons Attribution License (http://creativecommons.org/licenses/by/2.0), which permits unrestricted use, distribution, and reproduction in any medium, provided the original work is properly cited.

\section{Methods}

A collection of 1491 unrelated ASD cases were genotyped using either the Illumina 1M (993) or the Affymetrix SNP 6.0 platforms (498). The ASD subjects, all diagnosed using gold-standard instruments including Autism Diagnostic Interview and Autism Diagnostic Observation Schedule, are described elsewhere [16,17]. Informed written consent was obtained from all participants, as approved by the Research Ethics Boards at The Hospital for Sick Children

\section{Biomed Central}

of the Neuroligin (NLGN3, NLGN4) [3], Neurexin (NRXN1 [4], NRXN2 [5], NRXN3 [6]), SHANK (SHANK1 [7], SHANK2 [8], SHANK3 [9]) families and Gephyrin [10] as highly-penetrant risk loci [2]. ASD subjects with ultiple genetic risk factors for ASD and associated meda few examples of mutations in ASD cases identified in non-genic segments of DNA [12] and non-coding RNAs 13]. Similar findings are even better documented in in $\sim 40 \%$ of cases of ASD. Focusing on the intergenic intervals of the genome, we performed a systematic genomewide investigation to identify rare $\mathrm{CNVs}$ enriched in cases compared with controls [16] to identify known and novel ASD susceptibility loci. 
A

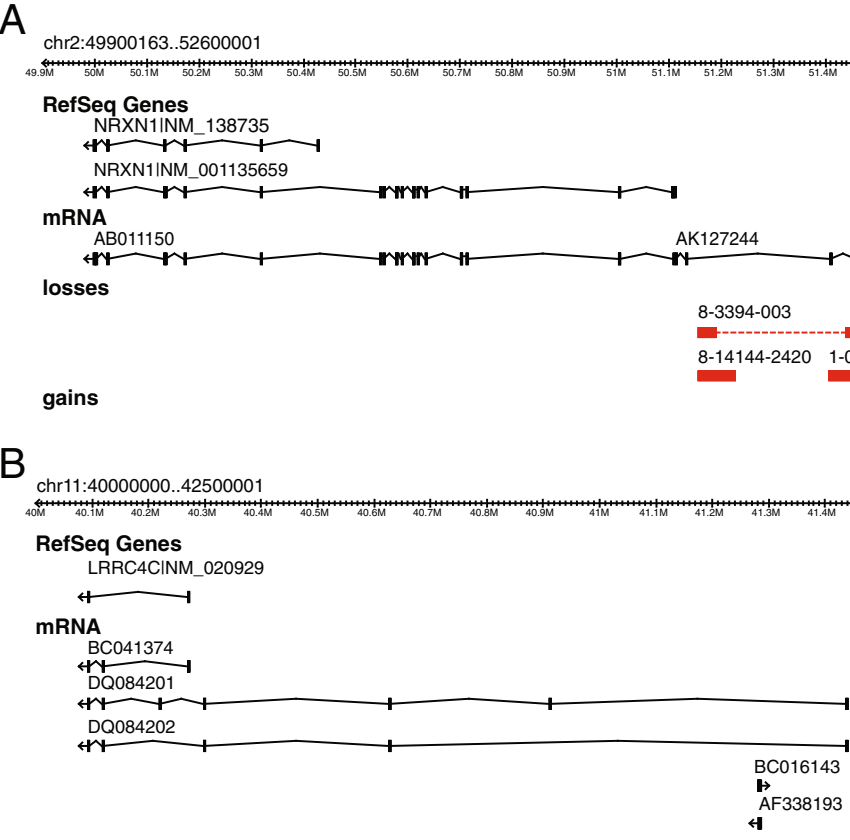

Human ESTs

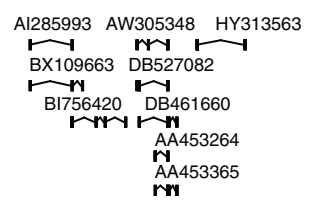

losses
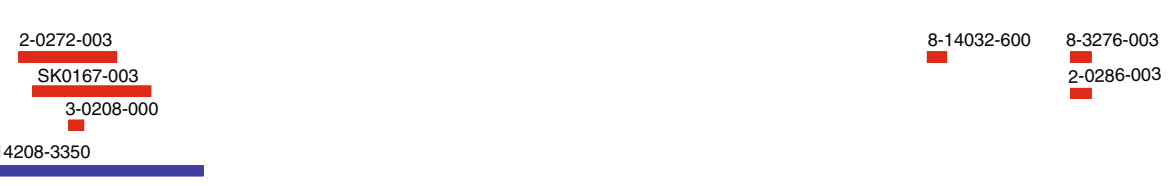

gains 8-14208-3350

C chr8:34900000..3580000

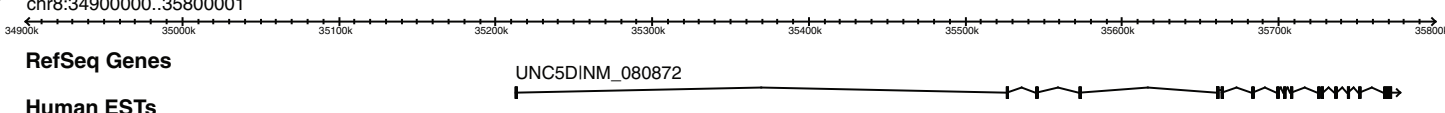

Human ESTs
BU853854

losses '

8-14243-3670

3-0044-000

8-14181-2940

3-0300-000

D

chr4:65830000..67200001

RefSeq Genes

Ref GHAINM 182472

EPHA5INM_182472

Human ESTs
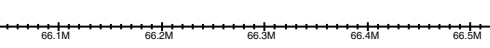

LOC100144602INR_034138 $\underset{\text { DA797949 }}{\text { Wry }}$

DA753080

DA715718

DB072214 HY185285

HY

1-0496-003

LOC100507205INR_038309 LOC10050

AY726565 trrmiry

Al285993 AW305348 HY313563 BX109663 B1 AA453264 AA453365 
and McMaster University. For controls, 1287 samples from the SAGE cohort were genotyped on with the Illumina $1 \mathrm{M}$ and 1234 samples from the Ottawa Heart Institute (OHI) and 1123 from the POPGEN collections were genotyped on the Affymetrix SNP 6.0. CNV discovery was performed using previously described pipelines [16-18]. Three CNV detection tools were used for each platform (Birdsuite, iPattern and Genotyping Console for Affymetrix 6.0 and iPattern, QuantiSNP \& PennCNV for Illumina $1 \mathrm{M}$ ). A subset of CNVs in both cases and controls were considered rare if they were present in $<1 \%$ of the overall dataset and these were further analysed if they failed to intersect or fall within a known gene (according to the NCBI Reference Sequence (RefSeq), August 2011). Rare genic CNVs identified from these data have been reported previously and from these data approximately $10 \%$ of cases carry a de novo or rare inherited $\mathrm{CNV}$ thought to contribute to ASD in that individual $[16,17,19,20]$. All CNVs discussed were validated where DNA was available using independent laboratory methods such as long range or quantitative PCR and the mode of inheritance determined (Additional files 1 and 2).

\section{Results and discussion}

Microarray data from a cohort of 1491 unrelated ASD probands were analysed for rare copy number variants as described previously $[16,17]$ and CNVs falling outside of known coding sequence were identified. A total of 212 non-coding genomic regions were determined as harboring overlapping CNVs in two or more unrelated ASD cases that were absent in control samples. Each region was examined for plausible biological function by comparison with multiple databases. Data was collated for evidence of expressed sequences from mRNA or EST data at GenBank or evolutionary conservation as well as functional predictions from the VISTA enhancer browser (http://enhancer.lbl.gov/) and Rfam (http://rfam.sanger.ac. $\mathrm{uk} /$ ). The Database of Genomic Variants (http://dgvbeta. tcag.ca/dgv/app/home) was used to eliminate additional regions as non-ASD specific $\mathrm{CNVs}$ and regions with $>80 \%$ masked as repetitive sequences were removed. Loci were also prioritised as being of potential clinical significance in ASD due to proximity to genes considered known or candidate ASD risk genes [17].

Fifteen intergenic regions emerged as plausible candidate ASD risk loci and in all instances the defining CNV events were inherited. In one of these regions, an additional case (SK0167-003) was found with an overlapping CNV described by Marshall et al. (2008) [19] (Table 1, Figure 1 and Additional files 1 and 2). In 14 of 15 , the intergenic interval identified has not been described before and in three regions the CNV neighboured a known ASD gene, namely, CDH8 [21], C3orf58 [22] and NRXN1 [4]. In the case of the NRXN1 gene, upstream CNVs found in five individuals impact the same mRNA (AK127244) reported elsewhere with a $\mathrm{CNV}$ in a family with ASD (Table 1, Figure 1A) [23]. Examples of other intergenic CNVs identified highlight regions at $8 \mathrm{q} 24.12$ upstream of $Z H X 2,6 \mathrm{p} 21.2$ upstream of MOCS1, 11p12 upstream of LRRC4C (Figure 1B) and 7q21.11 upstream of SEMA3C, as putative novel ASD rearrangements. In one case (8-14208-3350), deletions were identified at three separate loci; $4 \mathrm{q} 13.1$ upstream of EPHA5, 11p14.3 upstream of LUZP2 and $11 \mathrm{p} 12$ upstream of $L R R C 4 C$ and another case (3-0496-003) carried a 46, XXY sex chromosome imbalance. Other CNVs found in these 41 cases are shown in Additional file 3 and any or all of these may be contributing to the genetic load for ASD [11,17]. Interestingly, all the CNVs identified through our analysis are inherited events. The significance of this observation is still to be determined but suggests incomplete and/or variable penetrance of phenotype, which is something often observed in ASD $[6,7,17]$.

The mechanism of action of these rare CNVs in the pathogenesis of ASD could be (i) through altering the necessary copy number or positional context of key DNA sequence elements required for regulating the proper expression of nearby genes [1], (ii) affecting still undiscovered genes or non-coding RNAs residing in the CNV regions and (iii) disrupting uncharacterized isoforms of the adjacent annotated genes. In the first scenario, we find CNVs both upstream (e.g. UNC5D (Figure 1C), MOCS1, ASTN2, SEMA3C, ZHX2, LUZP2, CDH8) and downstream (C3orf58, RXRA, MRGPRD) of known ASD risk genes and putative novel loci. For at least three regions (4q13.1, 6p21.2 and 11p12 (shown in Figure 1D, Additional file $1 \mathrm{C}$ and Figure $1 \mathrm{~B}$ respectively)), our CNV mapping data in fact identify two distinct clusters of CNVs at the same locus, all overlapping spliced ESTs and thus with a possible regulatory role. Secondly, three independent CNV deletions interrupting a collection of spliced expressed sequenced tags approximately $330 \mathrm{~kb}$ proximal to EPHA5 highlight a potentially newly discovered ASD 
Table 1 ASD specific CNVs in intergenic regions

\begin{tabular}{|c|c|c|c|c|c|c|c|c|}
\hline Locus & Gene & Sample & CNV & Start & End & Size & $\begin{array}{l}\text { Furthest distance } \\
\text { from gene }\end{array}$ & Bin \\
\hline \multirow[t]{6}{*}{$2 p 16.3$} & NRXN1 AK127244 mRNA & 1-0045-004 & loss & 51405882 & 51524684 & 118802 & 1124 & ii \\
\hline & & 8-3394-003 & loss & 51439897 & 51479683 & 39786 & & \\
\hline & & 8-3394-003 & loss & 51157414 & 51189362 & 31948 & & \\
\hline & & $8-14144-2420$ & loss & 51157414 & 51225851 & 68437 & & \\
\hline & & 1-0496-003 & gain & 52220120 & 52238172 & 18052 & & \\
\hline & & 1-0449-003 & loss & 52237072 & 52253660 & 16588 & & \\
\hline \multirow[t]{2}{*}{$3 p 22.3$} & ARPP21 & $2-1213-003$ & loss & 34984049 & 35102773 & 118724 & 563 & ii \\
\hline & & $3-0100-000$ & gain & 35086691 & 35094736 & 8045 & & \\
\hline \multirow[t]{2}{*}{$3 q 24$} & C3orf58 ZICI, ZIC4 & 1-0007-003 & loss & 146168760 & 146934953 & 766193 & 1383 1955, 1979 & i \\
\hline & & 8-3093-004 & loss & 146575437 & 146631141 & 55704 & & \\
\hline \multirow[t]{5}{*}{$4 q 13.1$} & EPHA5 & $8-14208-3350$ & loss & 66505324 & 66633530 & 128206 & 840 & i \\
\hline & & 8-14186-3050 & loss & 66515708 & 66633530 & 117822 & & \\
\hline & & 1-0138-004 & loss & 66515708 & 66633530 & 117822 & & \\
\hline & & 2-0082-004 & loss & 67045815 & 67134170 & 88355 & & \\
\hline & & $1-0455-003$ & loss & 67058506 & 67075558 & 17052 & & \\
\hline \multirow[t]{4}{*}{$6 p 21.2$} & MOCS1 & 3-0139-000 & gain & 40021898 & 40078515 & 56617 & 168 & i or ii \\
\hline & & 2-0139-003 & gain & 40023327 & 40062155 & 38828 & & \\
\hline & & 1-0381-003 & loss & 40174188 & 40209324 & 35136 & & \\
\hline & & $2-1368-003$ & loss & 40174188 & 40210694 & 36506 & & \\
\hline \multirow[t]{2}{*}{$7 q 21.11$} & SEMA3C & $8-6258-03$ & loss & 80431202 & 80512022 & 80820 & 96 & i \\
\hline & & $1-0345-005$ & loss & 80482597 & 80517630 & 35033 & & \\
\hline \multirow[t]{4}{*}{$8 p 12$} & UNC5D NRG1 & $8-14243-3670$ & loss & 34923482 & 34956067 & 32585 & 2562183 & i \\
\hline & & 3-0044-000 & loss & 34923482 & 34956067 & 32585 & & \\
\hline & & 3-0300-000 & loss & 34925149 & 34957854 & 32705 & & \\
\hline & & 8-14181-2940 & loss & 34923482 & 34956067 & 32585 & & \\
\hline \multirow[t]{2}{*}{$8 q 24.13$} & $Z H X 2$ & 8-3317-003 & gain & 123572785 & 123625681 & 52896 & 237 & i or ii \\
\hline & & 3-0186-000 & loss & 123583028 & 123639417 & 56389 & & \\
\hline \multirow[t]{2}{*}{ 9q33.1 } & ASTN2 & 8-3055-004 & loss & 119254497 & 119374796 & 120299 & 98 & i \\
\hline & & $3-0115-000$ & loss & 119314967 & 119319559 & 4592 & & \\
\hline \multirow[t]{2}{*}{$9 q 34.2$} & OLFM1 RXRA & $2-1272-003$ & gain & 136479329 & 136604233 & 124904 & 5088 & i \\
\hline & & 2-1189-003 & gain & 136480334 & 136598491 & 118157 & & \\
\hline \multirow[t]{3}{*}{$11 p 14.3$} & LUZP2 & $8-14175-2820$ & loss & 24177612 & 24316053 & 138441 & 160 & i or ii \\
\hline & & 8-14059-1020 & loss & 24262511 & 24303132 & 40621 & & \\
\hline & & $8-14208-3350$ & loss & 24262511 & 24303132 & 40621 & & \\
\hline \multirow[t]{4}{*}{$11 \mathrm{p} 12$} & $\angle R R C 4 C$ & $8-14208-3350$ & gain & 40304880 & 40703298 & 398418 & 196 & iii \\
\hline & & $2-0272-003$ & loss & 40379668 & 40550356 & 170688 & & \\
\hline & & SK0167-003 & loss & 40417554 & 40610400 & 192846 & & \\
\hline & & $3-0208-000$ & loss & 40468058 & 40492541 & 24483 & & \\
\hline \multirow[t]{3}{*}{$11 \mathrm{p} 12$} & $\angle R R C 4 C$ & $8-14032-600$ & loss & 41990280 & 42021250 & 30970 & 1738 & i or ii \\
\hline & & 8-3276-003 & loss & 42243624 & 42279094 & 35470 & & \\
\hline & & 2-0286-003 & loss & 42243624 & 42279094 & 35470 & & \\
\hline \multirow[t]{2}{*}{$11 \mathrm{q} 13.2$} & MRGPRD & 4-0023-003 & loss & 68486121 & 68493638 & 7517 & 10 & i \\
\hline & & $2-1075-003$ & loss & 68486121 & 68500238 & 14117 & & \\
\hline \multirow[t]{2}{*}{$16 q 21$} & $\mathrm{CDH} 8$ & $8-14251-3750$ & loss & 61650435 & 61787984 & 137549 & 1030 & i or ii \\
\hline & & $2-1175-003$ & loss & 61658675 & 61755232 & 96557 & & \\
\hline
\end{tabular}

Location and size of all CNVs discovered are listed with the proposed associated candidate gene. Bin denotes possible mechanism of action by i) altering sequence elements required for regulating expression of neighboring genes ii) affecting undiscovered genes or non-coding RNAs iii) disrupting uncharacterised isoforms of adjacent genes. Genome browser views of all loci are shown in Figure 1 and Additional file 1. All pedigrees are shown in Additional file 2. Additional sample SK0167-003 identified in reference [19]. 
risk gene (Figure 1D). Finally, longer isoforms of $L R R C 4 C$ likely exist given the discovery of mRNAs DQ084201 and DQ084202. There are, of course, other functional DNA elements or modifications that need to be considered [24] as the mapping resolution increases.

\section{Conclusions}

Given the challenges faced in interpreting the clinical significance of multitudes of genetic variants found in for example, whole genome sequencing [25], accruing evidence across multiple studies will advocate loci outside of known genes or other regulatory elements for further study, particularly for rare variants. In this light, these data provide a useful resource for comparison as new data sets of both CNVs and nucleotide-level variants become available to help fine-map additional discover new ASD risk loci. This general research strategy can also be applied to other disease gene studies.

\section{Additional files}

\section{Additional file 1: Genome Browser views of loci with ASD specific} CNVs.

Additional file 2: Pedigree structure for all families listed in Table 1.

Additional file 3: Table of all rare CNVs detected in the individuals described herein.

\section{Competing interests}

The authors declare that they have no competing interests.

\section{Authors' contributions}

SW and SWS conceived the project and wrote the manuscript. SW designed the analysis, interpreted the data and conducted laboratory validation experiments. Both authors read and approved the final manuscript.

\section{Acknowledgements \\ Supported by NeuroDevNet, Genome Canada, the Ontario Genomics Institute, The Government of Ontario, the Canadian Institute of Health Research (CIHR), the Canadian Institute for Advanced Research, The McLaughin Centre, the Canadian Foundation for Innovation and the Ontario Ministry of Research and Innovation. SW holds a joint CIHR Autism Research Training and NeuroDevNet post-doctoral Fellowship. SWS holds the GlaxoSmithKline-CIHR Chair in Genome Sciences at the University of Toronto and The Hospital for Sick Children. We thank The Centre for Applied Genomics for technical contributions. We also acknowledge the assistance of Ines Sousa, Astrid Vicente, Alistair Pagnamenta, Richard Holt, Anthony Monaco, Catalina Betancur and Sylvia Lamoureux for assistance with CNV validation experiments.}

Received: 22 January 2013 Accepted: 20 July 2013 Published: 24 July 2013

\section{References}

1. Klopocki E, Mundlos S: Copy-number variations, noncoding sequences, and human phenotypes. Annu Rev Genomics Hum Genet 2011, 12(1):53-72.

2. Devlin B, Scherer SW: Genetic architecture in autism spectrum disorder. Curr Opin Genet Dev 2012, 22(3):229-237.

3. Jamain S, Quach H, Betancur C, Rastam M, Colineaux C, Gillberg IC, Soderstrom H, Giros B, Leboyer M, Gillberg C, et al: Mutations of the X-linked genes encoding neuroligins NLGN3 and NLGN4 are associated with autism. Hum Genet 2003, 34(1):27-29.
4. Szatmari $P$, Paterson AD, Zwaigenbaum L, Roberts W, Brian J, Liu XQ Vincent JB, Skaug JL, Thompson AP, Senman L, et al: Mapping autism risk loci using genetic linkage and chromosomal rearrangements. Nat Genet 2007, 39(3):319-328.

5. Gauthier J, Siddiqui T, Huashan P, Yokomaku D, Hamdan F, Champagne N, Lapointe M, Spiegelman D, Noreau A, Lafrenière R, et al: Truncating mutations in NRXN2 and NRXN1 in autism spectrum disorders and schizophrenia. Hum Genet 2011, 130(4):563-573.

6. Vaags Andrea K, Lionel Anath C, Sato D, Goodenberger M, Stein Quinn P, Curran S, Ogilvie C, Ahn Joo W, Drmic I, Senman L, et al: Rare deletions at the neurexin 3 locus in autism spectrum disorder. Am J Hum Genet 2012, 90(1):133-141.

7. Sato D, Lionel Anath C, Leblond Claire S, Prasad A, Pinto D, Walker S, O'Connor I, Russell C, Drmic Irene E, Hamdan Fadi F, et al: SHANK1 Deletions in males with autism spectrum disorder. Am J Hum Genet 2012, 90(5):879-887.

8. Berkel S, Marshall CR, Weiss B, Howe J, Roeth R, Moog U, Endris V, Roberts $W$, Szatmari $P$, Pinto $D$, et al: Mutations in the SHANK2 synaptic scaffolding gene in autism spectrum disorder and mental retardation. Nat Genet 2010, 42(6):489-491.

9. Moessner R, Marshall CR, Sutcliffe JS, Skaug J, Pinto D, Vincent J, Zwaigenbaum L, Fernandez B, Roberts W, Szatmari P, et al: Contribution of SHANK3 mutations to autism spectrum disorder. Am J Hum Genet 2007, 81(6):1289-1297.

10. Lionel AC, Vaags AK, Sato D, Gazzellone MJ, Mitchell EB, Chen HY, Costain G, Walker S, Egger G, Thiruvahindrapuram B, et al: Rare exonic deletions implicate the synaptic organizer gephyrin (GPHN) in risk for autism schizophrenia and seizures. Hum Mol Genet 2013, 22(10):2055-2066.

11. Leblond CS, Heinrich J, Delorme R, Proepper C, Betancur C, Huguet G, Konyukh M, Chaste P, Ey E, Rastam M, et al: Genetic and functional analyses of SHANK2 mutations suggest a multiple Hit model of autism spectrum disorders. PLOS Genet 2012, 8(2):e1002521.

12. Noor A, Whibley A, Marshall CR, Gianakopoulos PJ, Piton A, Carson AR, OrlicMilacic M, Lionel AC, Sato D, Pinto D, et al: Disruption at the PTCHD1 locus on Xp22.11 In autism spectrum isorder and intellectual disability. Sci Transl Med 2010, 2(49):49ra68.

13. Kerin T, Ramanathan A, Rivas K, Grepo N, Coetzee GA, Campbell DB: A noncoding RNA antisense to moesin at 5p14.1 In autism. Sci Trans/ Med 2012, 128:128ra140.

14. Bonnet C, Masurel-Paulet A, Khan AA, Béri-Dexheimer M, Callier P, Mugneret F, Philippe C, Thauvin-Robinet C, Faivre L, Jonveaux P: Exploring the potential role of disease-causing mutation in a gene desert: duplication of noncoding elements $5^{\prime}$ of GRIA3 is associated with GRIA3 silencing and X-linked intellectual disability. Hum Mutat 2012, 33(2):355-358.

15. Huang L, Jolly Lachlan A, Willis-Owen S, Gardner A, Kumar R, Douglas E, Shoubridge C, Wieczorek D, Tzschach A, Cohen M, et al: A noncoding, regulatory mutation implicates HCFC1 in nonsyndromic intellectual disability. Am J Hum Genet 2012, 91(4):694-702.

16. Lionel AC, Crosbie J, Barbosa N, Goodale T, Thiruvahindrapuram B, Rickaby J, Gazzellone M, Carson AR, Howe JL, Wang Z, et al: Rare copy number variation discovery and cross-disorder comparisons identify risk genes for ADHD. Sci Transl Med 2011, 3(95):95ra75.

17. Pinto D, Pagnamenta AT, Klei L, Anney R, Merico D, Regan R, Conroy J, Magalhaes TR, Correia C, Abrahams BS, et al: Functional impact of global rare copy number variation in autism spectrum disorders. Nature 2010, 466(7304):368-372.

18. Pinto D, Darvishi K, Shi X, Rajan D, Rigler D, Fitzgerald T, Lionel AC, Thiruvahindrapuram B, MacDonald JR, Mills R, et al: Comprehensive assessment of array-based platforms and calling algorithms for detection of copy number variants. Nat Biotech 2011, 29(6):512-520.

19. Marshall CR, Noor A, Vincent JB, Lionel AC, Feuk L, Skaug J, Shago M, Moessner $R$, Pinto $D$, Ren $Y$, et al: Structural variation of chromosomes in autism spectrum disorder. Am J Hum Genet 2008, 82(2):477-488.

20. Prasad A, Merico D, Thiruvahindrapuram B, Wei J, Lionel AC, Sato D, Rickaby J, Lu C, Szatmari P, Roberts W, et al: A discovery resource of rare copy number variations in individuals with autism spectrum disorder. G3 (Bethesda) 2012, 2(12):1665-1685.

21. Pagnamenta AT, Khan H, Walker S, Gerrelli D, Wing K, Bonaglia MC, Giorda R, Berney T, Mani E, Molteni M, et al: Rare familial 16q21 microdeletions under a linkage peak implicate cadherin $8(\mathrm{CDH} 8)$ in susceptibility to autism and learning disability. J Med Genet 2011, 48(1):48-54. 
22. Morrow EM, Yoo S-Y, Flavell SW, Kim T-K, Lin Y, Hill RS, Mukaddes NM, Balkhy S, Gascon G, Hashmi A, et al: Identifying autism loci and genes by tracing recent shared ancestry. Science 2008, 321(5886):218-223.

23. Ching MSL, Shen Y, Tan W-H, Jeste SS, Morrow EM, Chen X, Mukaddes NM, Yoo S-Y, Hanson E, Hundley R, et al: Deletions of NRXN1 (neurexin-1) predispose to a wide spectrum of developmental disorders. Am J Med Genet B Neuropsychiatr Genet 2010, 153B(4):937-947.

24. The ENCODE Project Consortium: An integrated encyclopedia of DNA elements in the human genome. Nature 2012, 489(7414):57-74.

25. Jiang Y-h, Yuen Ryan KC, Jin X, Wang M, Chen N, Wu X, Ju J, Mei J, Shi Y, He M, et al: Detection of Clinically Relevant Genetic Variants in Autism Spectrum Disorder by Whole-Genome Sequencing. Am J Hum Genet 2013, http://dx.doi.org/10.1016/j.ajhg.2013.06.012.

\section{doi:10.1186/1471-2164-14-499}

Cite this article as: Walker and Scherer: Identification of candidate intergenic risk loci in autism spectrum disorder. BMC Genomics 2013 14:499.

\section{Submit your next manuscript to BioMed Central and take full advantage of:}

- Convenient online submission

- Thorough peer review

- No space constraints or color figure charges

- Immediate publication on acceptance

- Inclusion in PubMed, CAS, Scopus and Google Scholar

- Research which is freely available for redistribution 